\title{
Analisis Nilai Resistivitas Tanah Perkebunan Berdasarkan Variasi Kadar Air
}

\author{
Gisela Adelita ${ }^{*}$, Ardi Rizkia Ferahenki ${ }^{1}$, Mimin Iryanti $^{1}$, Ahmad Aminudin ${ }^{1}$ \\ ${ }^{1}$ Program Studi Fisika, Universitas Pendidikan Indonesia, Jl. Dr. Setiabudhi 229 Ban- \\ dung 40154, Indonesia \\ ${ }^{2}$ Laboratorium Bumi dan Antariksa, Universitas Pendidikan Indonesia, Jl. Dr. Setiabudhi \\ 229 Bandung 40154, Indonesia \\ E-mail: giselaadelita12@gmail.com (Nanang Dwi Ardi), \\ Telp: 0895368414870
}

\begin{abstract}
ABSTRAK
Nilai resistivitas pada setiap material tentu akan berbeda-beda tergantung dari berbagai faktor seperti kadar air dan distribusi butiran tanah. Pada penelitian, sampel tanah diambil dari perkebunan kampung pasir biru, desa rancakole. Sampel dibuat suatu keadaan tanah homogen yang diletakan pada wadah. Nilai resistivitasnya bisa didapat menggunakan metode geolistrik dengan konfigurasi wenner. Penelitian ini menggunakan metode sieve analisis yang berguna untuk mengetahui distribusi butiran tanah. Penelitian ini mendapatkan hasil bahwa pada kondisi kadar air (0\%), nilai resistivitas semakin kecil saat titik tengah pada konfigurasi wenner berada di 0,15 m yaitu sebear 97,68 Ohm.m. Hubungan antara permeabilitas dengan resistivitas dapat dijelaskan dengan menghubungkan hukum Darcy dan hukum Ohm yaitu konduktivitas hidraulik (permeabilitas) berbanding lurus dengan konduktivitas dan berbanding terbalik dengan resistivitas. Tanah pada penelitian ini setelah dianalisis terhadap distribusi butiran tanah didapatkan bahwa tanah termasuk lempung berpasir yang memiliki permeabilitas rendah $\left(10^{-5}-10^{-7}\right)$.
\end{abstract}

Kata Kunci : Resistivitas, analisis saringan, permeabilitas, hukum Darcy 


\begin{abstract}
Resistivity values in each material certainly vary depending on various factors such as water content and distribution of soil grains. In this study, soil samples were taken from plantations pasir biru, rancakole village. Samples are made on homogeneous soil conditions placed in the box. The value of resistivity can be obtained using the geoelectric method with a Wenner setting. This study uses an analysis filter method that is useful to determine the distribution of soil grains. This study gets results the resistivity value gets smaller when the midpoint of the Wenner configuration is at 0.15 $m$ which is equal to 97.68 Ohm.m at water content (0\%). The relationship between permeability and resistance can be combined by connecting Darcy and Ohm's law, ie hydraulic conductivity (permeability) is directly proportional to conductivity and inversely proportional to resistivity. After the analysis of soil granular distribution, the study found that the soil contains sandy clay which had low permeability (10-5-10-7).
\end{abstract}

Keywords: Resistivity, sieve analysis, permeability, Darcy's law

\section{Pendahuluan}

Bumi tersusun atas komposisi batuan yang bersifat heterogen, sehingga menyebabkan harga resistivitas yang berbeda. Menurut Rolia [1] ada beberapa faktor yang mempengaruhi nilai resistivitas pada batuan yaitu jenis material, kandungan air, porositas batuan dan sifat kimia. Nilai resistivitas batuan dapat diketahui dengan melakukan penelitan dengan metode geofisika yaitu menggunakan resistivity meter. metode geofisika ini umumnya mengaggap bumi satu lapisan sehingga parameter yang didapat merupakan parameter semu $[2,3]$.
Porositas merupakan salah satu faktor yang menentukan nilai resistivitas suatu batuan. Perbedaan porositas disebabkan oleh perbedaan tekstur tanah, yaitu perbandingan relatif berbagai ukuran partikel (separasi/fraksi) dalam tanah [3]. Kelas tekstur tanah diklasifikasi berdasarkan perbandingan banyaknya butir pasir, debu dan tanah liat. Tanah dengan tekstur liat mempunyai luas permuaan yang besar sehingga memiliki kemampuan Menahan air dan menyediakan unsur hara yang tinggi [4].

Penelitian ini bertujuan untuk mengetahui pengaruh kadar air dan distribusi butiran tanah terhadap nilai 
resistivitas. Pengukuran resistivitas tanah dilakukan dengan menggunakan metode geolistrik resistivitas konfigurasi wenner. Konsep dasar dari metode geolistrik adalah hukum Ohm yang menyatakan bahwa beda potensial yang timbul di ujung-ujung suatu medium berbanding lurus dengan arus listrik yang mengalir. Ohm ini juga menyatakan bahwa tahanan jenis listrik berbanding lurus dengan panjang medium dan berbanding terbalik dengan luas penampangnya [6]. Hukum Ohm ini dapat dinyatakan dalam persamaan 1 berikut.

$$
R \sim \frac{L}{A} \text { atau } R=\rho \frac{L}{A}
$$

Objek tanah yang akan diukur nilai resistivitasnya adalah tanah perkebunan di kampung Pasir Biru, Desa Rancakole, Kecamatan Arjasari, Kabupaten Bandung. Klasifikasi tekstur tanah dapat dilakukan dengan metode saringan. cara yang dipilih yaitu cara basah.

\section{Bahan dan Metode}

Sampel tanah diambil dari kampung Pasir Biru, Desa Rancakole, Kecamatan Arjasari, Kabupaten Bandung. Kondisi geografis kecamatan arjasari berbukitbukit karena merupakan hulu DAS Citarum dengan ketinggian $800 \mathrm{mdpl}$ hingga $1.250 \mathrm{mdpl}$.

Data yang diperoleh dari penelitian ini adalah nilai resistivitas pada tanah kebun dengan metode geolistrik kebun dengan metode geolistrik konfigurasi wenner. Penelitian ini dilakukan melalui beberapa tahap yaitu mengklasifikasikan tanah dengan menggunakan metode basah yaitu menyaring tanah agar ukurannya homogen. Tanah homogeny tersebut kemudian dikeringkan. Tanah tersebut selanjutnya dimasukan kedalam wadah dan divariasikan kadar airnya dari 0\%, 5\% dan $10 \%$.

Selanjutnya nilai resistivitas pada masing-masing kondisi konsentrasi air pada tanah dapat diukur dengan cara menanam empat elektroda yang terdiri dari dua elektroda arus dan dua elektroda potensial. Nilai tegangan dan arus yang terukur pada setiap kondisi tersebutlah yang kemudian dianalisis pengaruh butiran tekstur tanah dengan Sieve Analysis terhadap nilai resistivitasnya.

Pada penelitian ini terdapat tiga lintasan dengan memvariasikan kadar air dan jaraknya. Ketiga lintasan tersebut adalah lintasan $\mathrm{AB}$, lintasan $\mathrm{CD}$, dan lintasan EF. Gambar 1 merupakan desain lintasan pada penelitian ini.

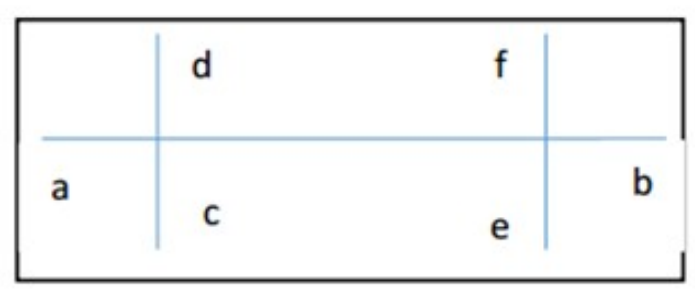

Gambar 1. Lintasan Elektroda 


\section{Hasil dan Pembahasan}

Hasil pengujian nilai resistivitas tanah pada lintasan $\mathrm{AB}, \mathrm{CD}$ dan $\mathrm{EF}$ ditunjukan pada gambar 2, 3 dan 4. Pada grafik terlihat bahwa nilainya semakin naik ketika semakin ditambahkan air. Hal ini dikarenakan kepadatan tanah yang kurang merata sehingga mempengaruhui porositas tanah. Porositas tanah ini juga disebabkan oleh distribusi butiran tanah dan permeabilitas tanah yang mempengaruhi kapasitasnya untuk menahan air.

Hasil dari sieve analysis, Persentase fraksi menggunakan USDA dapat diketahui bahwa presentase sand $47,81 \%$, silt $4,6 \%$ dan clay $47,6 \%$. Pada penelitian ini tanah yang menjadi sampel adalah tanah berliat atau jenis sandy clay liat berpasir. Menurut Hardiyatmo (2002) [7,8] bahwa tanah yang bertekstur liat memiliki pori-pori kecil sehingga menyebabkan permeabilitas rendah. Hubungan permeabilitas dengan resistivitas dapat dijelaskan oleh hukum Darcy dan hukum Ohm.

Hukum Darcy flux (q) menyatakan bahwa laju aliran dibagi dengan luas potongan melintang dan memiliki dimensi yang sama dengan kecepatan seperti pada persamaan 2 .

$$
q=-K \frac{d h}{t}
$$

$\mathrm{q}=$ flux alairan air

$\mathrm{k}=$ Hidraulik Konduktivitas $(\mathrm{m} / \mathrm{s})$

$\mathrm{t}=$ Ketebalan (m)

$\mathrm{dh}=$ perpindahan hidraulik head (m)

Sedangkan hukum Ohm menyatakan bahwa beda tegangan berbanding lurus dengan arus dan resistivitas seperti pada persamaan 3 dan 4 . Resistivitas sendiri merupakan sifat karakteristik suatu bahan yang menyatakan tingkat kesulitan dalam menghantarkan arus listrik.

$$
\begin{aligned}
& V=I R \\
& \qquad R=\frac{V}{I}
\end{aligned}
$$

Dan hubungan antara hukum Darcy dan Ohm dijelaskan pada persamaan 5 .

$$
K=A \frac{1}{\rho}
$$

Berdasarkan persamaan diatas dapat disimpulkan bahwa konduktivitas hidroulik berbanding lurus dengan konduktivitas dan berbanding terbalik dengan resistivitas.

Tanah sampel ini merupakan tanah liat berpasir yang sangat cocok untuk tanaman cabai (widodo,2012) [9]. Tanah liat berpasir ini juga cocok untuk ditanam pohon jeruk (Endarto, O. \& Martini, E, 2016)[10].

Dimana 


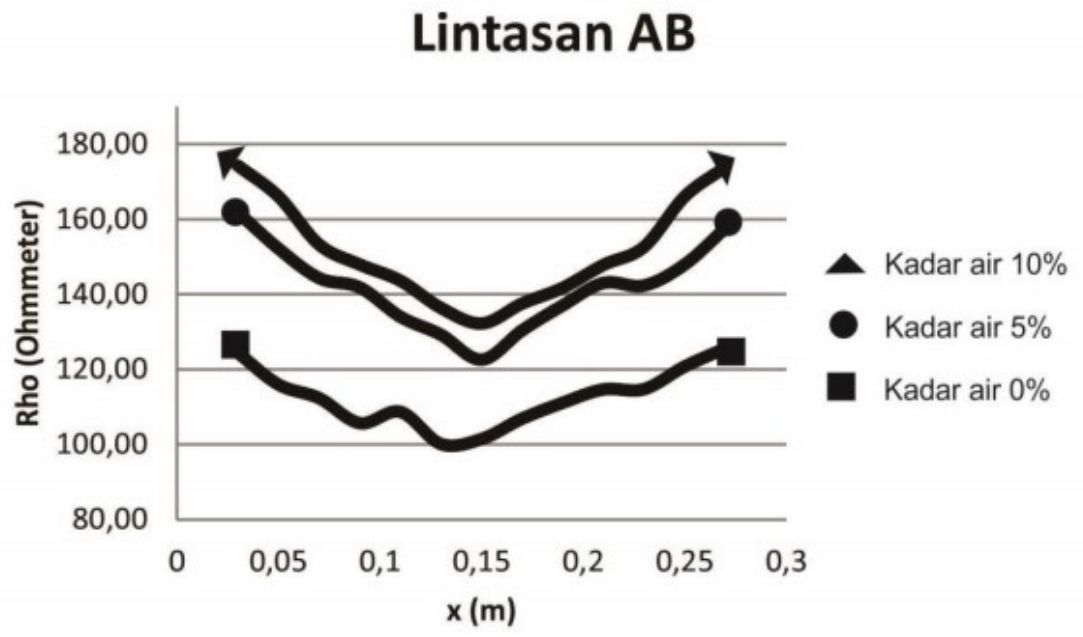

Gambar 2. Grafik Jarak terhadap Resistivitas (Lintasan AB)

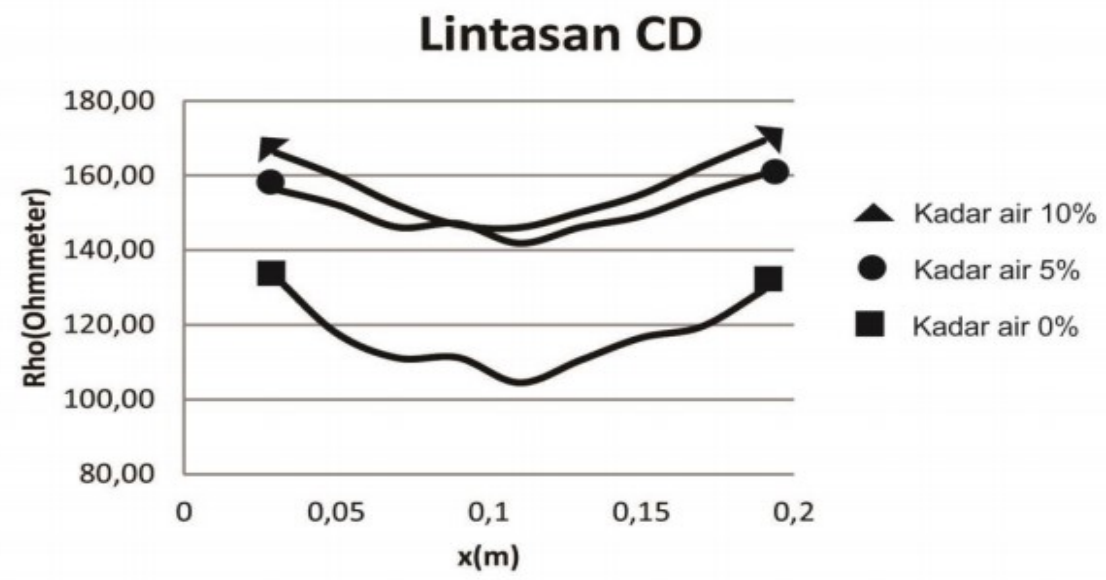

Gambar 3. Grafik Jarak terhadap Resistivitas (Lintasan CD)

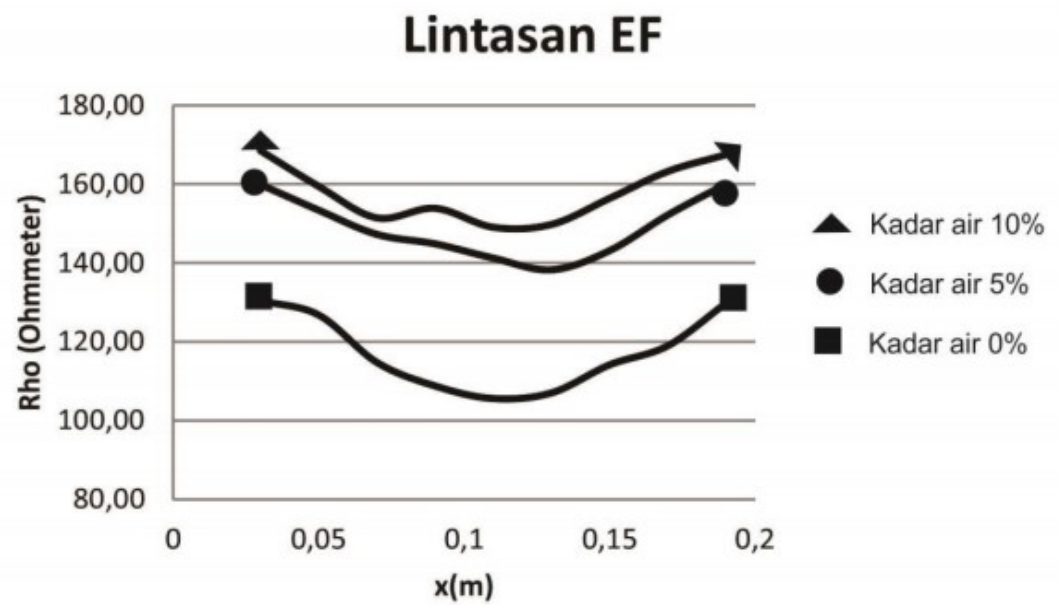

Gambar 4. Grafik Jarak terhadap Resistivitas (Lintasan EF) 


\section{Simpulan}

1. Tanah pada sampel merupakan jenis tanah liat berpasir dengan karakteristik memiliki nilai permeabilitas yang rendah.

2. Tanaman yang cocok untuk ditanami pada lahan dengan karakteristik tanah liat berpasir adalah pohon cabai dan pohon jeruk.

\section{Referensi}

1. Rolia, Eva. (2011). Penggunaan Metode Geolistrik untuk Mendeteksi Keberadaan Air tanah. Fakultas Teknik Universitas Muhammadiyah Metro. $\leftarrow$ Journal

2. Ferahenki, A.R., (2018). Aplikasi Pemograman Inversi 2D Menggunakan Matlab ${ }^{\circledR}$ pada Data Resistivitas. Seminar Nasional Fisika (SNF) 2018 UNESA. Surabaya. $\leftarrow$ Journal

3. Zaenudin, A., \& Dani, I. PEMODELAN 2D DAN 3D GEOLISTRIK TOMOGRAFI UNTUK INTERPRETASI BIDANG GELINCIR DAN ARAH ALIRAN AIR PADA STRUKTUR BAWAH PERMUKAAN REL KERETA API DI BATURAJA, SUMATERA SELATAN. Wahana Fisika, 4(2), 104110.

4. Pandutama, M.H., dkk. (2003). Dasar -dasar Ilmu Tanah (Buku Ajar). Fakultas Pertanian Universitas Jember. $\leftarrow$ Journal
5. Hardjowigeno, S. 1995. Kesesuaian Lahan untuk Pengembangan Pertanian Daerah Rekreasi dan Bangunan. Lembaga Pengabdian Kepada Masyarakat. IPB. Bogor. 200 hlm. $\leftarrow$ Journal

6. Asmoro, C. P., \& Susanti, H. (2020). Analysis of Do-it-Yourself (DIY) Electrode for Soil Resistivity Measurement Practical of Geology and Geophysics Subject at Earth and Outerspace Laboratory. Jurnal Temapela, 3(1), 10-18.

7. Hardiyatmo, H.C. (2002), Mekanika Tanah I Cetakan Pertama Edisi ketiga. Gadjah Mada University Press, Yogyakarta. $\leftarrow$ Book

8. Hardiyatmo, H.C. (2002), Mekanika Tanah II. Gadjah Mada University Press, Yogyakarta. $\leftarrow$ Book

9. Widodo, W. D. (2012). Memperpanjang Umur Produksi Cabai. Jakarta: Niaga Swadaya. $\leftarrow$ Journal

10. Endarto, O. \& Martini, E. (2016). Pedoman Budidaya Jeruk Sehat. Balai penelitian tanaman jeruk dan buah subtropika (balitjestro) bekerja sama dengan agfor Sulawesi. $\leftarrow$ Journal 